\title{
KAJIAN EFEKTIVITAS ORNAMEN GIGI BALANG SEBAGAI IDENTITAS INFRASTRUKTUR KOTA JAKARTA
}

\author{
Rahmiati Aulia \\ Program Studi Desain Komunikasi Visual, Fakultas Industri Kreatif, Telkom University, \\ JI. Telekomunikasi, Bandung, Jawa Barat, 40257 \\ raulia@telkomuniversity.ac.id
}

Received: 07 April 2020

Revised: 17 September 2020

Accepted: 17 Oktober 2020

\begin{abstract}
Abstrak: Jakarta sebagai ibukota provinsi Indonesia menjadi salah satu Kota dengan jumlah penduduk paling banyak. Melihat kembali latar belakang kebudayaan asli Jakarta atau yang dikenal dengan budaya Betawi dari asal kata Batavia. Budaya Betawi sendiri merupakan akulturasi dari adanya berbagai macam etnis dan budaya para pendatang. Budaya ini meliputi berbagai aspek seperti musik, tari, ragam hias dan lain sebagainya. Salah satu ragam hias khas Betawi yaitu ornamen Gigi Balang yang berdasarkan pada Pergub 11 Tahun 2017, ornamen ini dipilih untuk dijadikan identitas infrastruktur Kota Jakarta. Belum adanya kajian mengenai efektivitas penggunaan ornamen Gigi Balang dalam infrastruktur Kota Jakarta. Tujuan penelitian ini adalah menganalisa tingkat efektivitas ornamen Gigi Balang yang telah digunakan sebagai identitas infrastruktur Kota Jakarta yang dinilai melalui beberapa aspek yaitu; aspek bentuk, waktu, tempat dan fungsi utilitas. Metode analisa menggunakan Prinsip Totalitas, Waktu dan Nilai oleh W. H. Mayall yang dikembangkan oleh Dr. Ahadiyat Joedawinata dengan teknik pengumpulan data melalui observasi, wawancara, kuesioner, dokumentasi dan studi pustaka. Berdasarkan hasil survei, ornamen ini dinilai kurang efektif. Hal ini dibuktikan dengan hasil kuesioner yang menunjukkan kurangnya pemahaman penduduk Kota Jakarta terhadap ornamen Gigi Balang. Sehingga ornamen ini hanya dianggap sebagai elemen dekoratif tanpa mengetahui asal usul dan makna yang terkandung di dalamnya.
\end{abstract}

Kata kunci: Gigi Balang, Jakarta, identitas kota, ragam hias etnik.

\begin{abstract}
Jakarta as the capital city of Indonesia has become the most populous province in the country. Looking back at the original cultural background of Jakarta, known as Betawi culture of origin word Batavia, Betawi culture itself is an acculturation of the various ethnic groups and cultures of migrants. This culture includes various aspects such as music, dance, decoration, and others. The ornamental variety, namely Gigi Balang based on Pergub 11 Year 2017, is chosen to be the infrastructure identity of Jakarta. However, there is absence of studies on Gigi Balang ornament effectiveness as an infrastructure identity of the city. The purpose of this study was to analyze the
\end{abstract}


effectiveness of Gigi Balang as the identity assessed through several aspects: form, time, place and utility functions. The analytical method uses the Principle of Totality, Time and Value by W. H. Mayall, developed by Dr. Ahadiyat Joedawinata with data collection techniques through observation, interviews, questionnaires, documentation and literature study. Based on the survey results, this ornament is considered less effective. This is proofed by the results of a questionnaire that shows the low level of understanding by Jakarta citizens towards Gigi Balang. This ornament is only considered as a decorative element without knowing the origin and meaning contained.

Keywords: Gigi Balang, Jakarta, city identity, ethnic decoration.

\section{PENDAHULUAN}

Sejak dulu Jakarta menjadi tempat pembauran segala suku dan bangsa. Diduga dahulu Jakarta diduduki oleh sekelompok warga Salakanegara, yaitu kerajaan leluhur orang Sunda (Misno \& Prawiro, 2016), kemudian disusul oleh pedagang dan pelaut asing dari pesisir utara Jawa yang lambat laun memasuki wilayah Jakarta. Ada pula yang berasal dari Malaka, bahkan hingga bangsa luar seperti Tiongkok dan Gujarat dari India (Chaer, 2012). Bertemunya berbagai macam suku dan etnis dalam satu kawasan ini menjadi cikal bakal lahirnya budaya Betawi. Asal usul kata Betawi memiliki beberapa versi, namun yang jelas kata tersebut telah muncul sejak zaman Belanda pada masa kolonialisme. Peranan Bangsa Belanda cukup besar dalam pembentukan Suku Betawi. Sebutan Betawi sendiri ditujukan untuk suku asli yang menduduki Jakarta dengan Bahasa Melayu Kreol sebagai ciri khasnya (Nediari dan Hartanti, 2015). Sekitar tahun 1930 muncul kategori sensus baru sebagai Suku Betawi yang menjadi mayoritas pada saat itu sebanyak 778.953 jiwa (Dianty, 2017), yang merupakan masyarakat agraris (Casande, 2011). Suku Betawi bisa dikatakan sebagai pendatang baru di Jakarta yang diistilahkan sebagai anak ketiga. Pada urutan anak pertama adalah suku Jawa, anak kedua adalah suku Sunda dan ketiga adalah Betawi dengan perpaduan antara berbagai macam suku yang sudah terlebih dulu tinggal di Jakarta seperti: 
Ambon, Bali, Timor, Sumbawa, Tionghoa, Melayu, Arab, Cina dan Jepang (Windarsih, 2013), (Faizah, et al., 2018), (Untung, 2018).

Berdasarkan dari ciri khas kebudayaan, Betawi terbagi menjadi dua yaitu Betawi Kota dan Betawi Pinggiran. Perbedaan menonjol dari kedua Budaya Betawi tersebut dapat dilihat bahwa Betawi Kota dipengaruhi oleh budaya Muslim Melayu yang juga banyak mengalami tingkat arus urbanisasi dan modernisasi paling tinggi, sedangkan Betawi Pinggiran dipengaruhi oleh Budaya Tionghoa (Purbasari, 2010). Pengaruh dari nilai religius budaya Islam merupakan bagian dari keseharian yang sangat melekat pada masyarakat Betawi. Pengaruh perkembangan Islam sendiri salah satunya dibawa oleh pasukan Islam dari wilayah Demak dan Cirebon yang membawa pengaruh penggunaan ornamen pada batik seperti ragam hias khas Timur Tengah berupa medali, wajik, arabest (kembangkembangan) dan pengaruh dasar dari religi sendiri yaitu larangan menggambarkan bentuk makhluk hidup khususnya hewan dan manusia. Akulturasi pada Budaya Betawi juga ditemukan pada prosesi upacara adat istiadat yaitu khitan (sunat), pernikahan dan kematian. Proses upacara ini merupakan hasil percampuran dari Budaya Islam, Tionghoa dan unsur pra-Islam yang tidak hanya ada pada konsep budaya Hindu dan Budha.

Akulturasi tersebut juga menghasilkan berbagai kesenian dan budaya, yang salah satunya merupakan ornamen-ornamen pada arsitektur Betawi. Berbagai ornamen tersebut tidak hanya berfungsi sebagai penghias bangunan, akan tetapi mempunyai makna mendalam tentang falsafah dari masyarakat Betawi itu sendiri. Beberapa macam ornamen pada rumah betawi antara lain berupa lisplang, banji, langkan, bunga melati dan matahari (Amarena and Hartanti, 2015). Salah satu bentuk ornamen yang terdapat pada arsitektur Betawi adalah Gigi Balang. Berbentuk segitiga terbalik yang berjajar, terbuat dari kayu pada bagian lisplang rumah adat Betawi sebagai simbol gagah, kokoh dan berwibawa (Windyastuti, 2018). Bentuk segitiga terbalik ini menginterpretasikan sebuah 
gunung yang terinspirasi dari bentuk gigi belalang yang secara epistemologis ornamen ini mempunyai makna bahwa hidup harus selalu jujur, rajin, ulet dan sabar. Filosofi dari belalang yang dapat mematahkan kayu apabila menggigit kayu tersebut secara terus menerus hingga terpotong dalam waktu yang lama. Hal ini dimaknai dengan pertahanan yang kuat dan keberanian. Prinsip tersebut yang kemudian dipegang teguh oleh masyarakat Betawi. Adanya ornamen Gigi Balang yang mengelilingi teras rumah umumnya menggunakan warna khas budaya Betawi yaitu kuning dan hijau. Warna khas budaya Betawi sendiri banyak menggunakan warna-warna cerah, dikarenakan mendapat banyak pengaruh budaya akulturasi dari Tionghoa yang memiliki warna merah serta warna mencolok lainnya. Sedangkan warna hijau sendiri banyak dipengaruhi oleh budaya Islam yang berasal dari Timur Tengah (Purbasari, 2010).

Ornamen Gigi Balang pada masa sekarang banyak ditemukan di berbagai elemen infrastruktur Kota Jakarta seperti halte TransJakarta, jalan layang, pembatas jalan, jembatan penyeberangan orang (JPO), serta jalan lintas bawah (underpass). Hal ini merupakan upaya pemerintah lbu kota untuk mempertahankan budaya Betawi sebagai identitas Jakarta. Sesuai keputusan peraturan gubernur nomor 11 tahun 2017, bahwa budaya Betawi merupakan aset bangsa yang harus dilestarikan, yang memiliki peranan penting dalam membangun daya tarik wisata dan wujud jati diri Kota Jakarta sebagai kuali peleburan. Ikon Budaya Betawi sebagaimana dimaksud terdiri atas: ondel-ondel, kembang kelapa, ornamen Gigi Balang, baju sadariah, kebaya kerancang, batik betawi, kerak telor, dan bir pletok (jakarta-tourism.go.id, 2017).

Identitas budaya yang kuat akan memberikan impresi dan daya pikat wisata berdasar dari sumber peraturan gubernur. Selain itu, dengan adanya identitas Kota Jakarta diharapkan dapat menjadi pedoman dalam setiap aktivitas yang dilaksanakan oleh pemerintah, pelaku usaha dan juga warga masyarakat Jakarta dengan menjunjung tinggi nilai filosofis yang terkandung di dalamnya. 


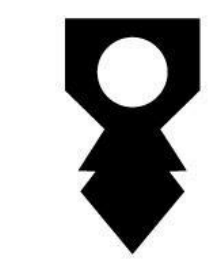

Kuntum Melati

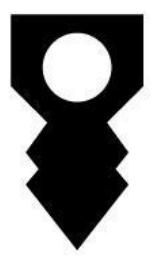

Tumpal

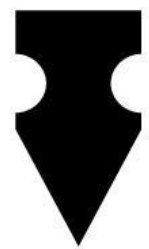

Potongan Waru



Wajik

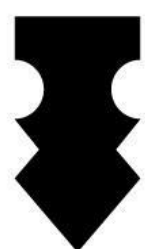

Wajik susun dua

Gambar 1. Ragam ornamen Gigi Balang Sumber: ilustrasi oleh Aulia, 2020

Pengaplikasian ornamen Gigi Balang pada infrastruktur seperti jembatan, pembatas jalan, ornamen pada halte bus dan lain sebagainya adalah salah satu upaya pemerintah untuk melestarikan budaya Betawi. Pada era digital ini pemerintah berusaha untuk tetap melestarikan kebudayaan daerah terutama Budaya Betawi sebagai ikon atau identitas Kota Jakarta. Dengan penuansaan tersebut, diharapkan menjadi ajang promosi budaya yang baik. Seperti pada moment menyambut ajang Asian Games 2018 yang diselenggarakan di Jakarta.

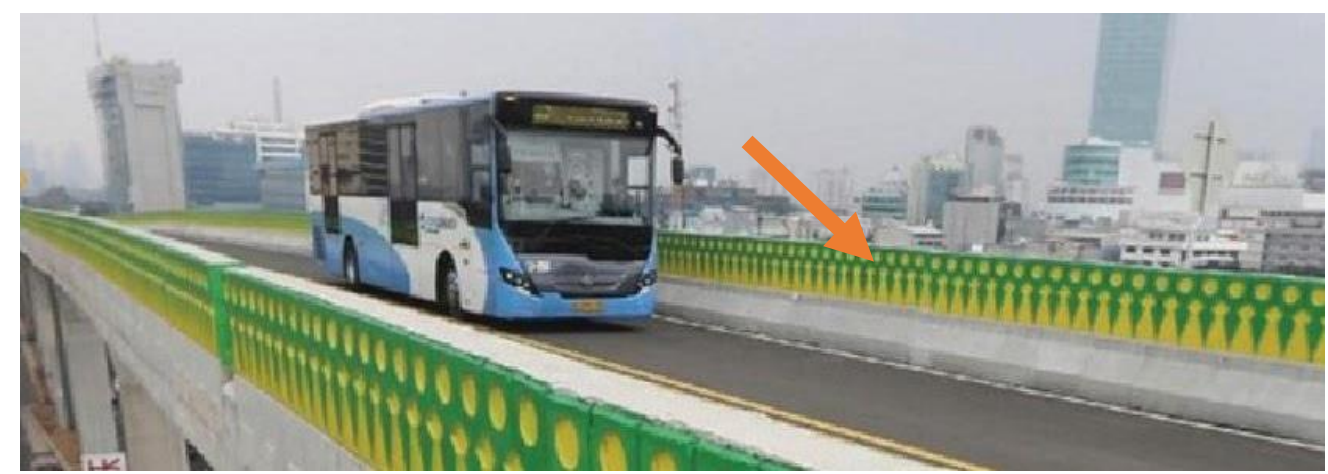

Gambar 2 Ornamen Gigi Balang pada pembatas jembatan Sumber: www.goodnewsfromindonesia.id, 2018

Dahulu penggunaan ornamen Gigi Balang biasa diaplikasikan pada lisplang rumah adat Betawi. Lisplang adalah bagian dari bangunan yang berfungsi untuk menutupi susunan kaso yang tampak pada bangunan sehingga dengan adanya lisplang, susunan kaso yang tertutup akan tampak lebih rapi ketika dilihat dari arah 
bawah. Fungsi lain dari lisplang juga mencegah binatang yang mampu menyusup dari atap lewat sela-sela kaso yang terekspos. Sebagai elemen sebuah bangunan, lisplang memiliki fungsi estetik dan utility yang seimbang.

Penggunaan ornamen pada arsitektur rumah adat Betawi biasanya diterapkan pada lubang angin, kusen, daun pintu, jendela, tiang, dinding di ruang depan, lisplang, garde (pembatas antara ruang tengah dengan ruang depan) dan pagar pada serambi yang dibuat dari bambu atau kayu. Terkait dengan ornamen Gigi Balang, dahulu ornamen ini hanya digunakan sebagai penghias bagian lisplang rumah adat Betawi, ragam hias yang ada pada rumah tradisional Betawi cenderung berbentuk sederhana, berupa ukiran pada kayu dengan ornamen geometris seperti titik, segi empat, belah ketupat, segitiga, lengkung, setengah lingkaran, dan lingkaran. Bagi rumah adat Betawi, ornamen atau dekorasi merupakan salah satu unsur bangunan paling penting pada arsitektur rumah tinggal (Nediari \& Hartanti, 2015). Meskipun rumah yang memiliki gaya arsitektur modern, Gigi Balang sebagai identitas rumah Betawi tetap digunakan hingga saat ini sebagai representasi dari Budaya Betawi (Rosalinda, et al., 2019).

Untuk gaya bangunan rumah adat Indonesia, lisplang seringkali menjadi ciri khas dari sebuah rumah adat karena dilengkapi dengan ukiran atau ornamen yang berbeda untuk masing-masing daerah. Lisplang yang berukir atau berornamen ini menjadi simbol kearifan masyarakat tradisional dalam menyiasati alam. Posisi lisplang yang terus menerus terpapar sinar matahari dan hujan, maka akan berpotensi menjadi kotor dalam waktu yang tidak terlalu lama. Maka fungsi dari ukiran atau ornamen lisplang ini adalah untuk menyamarkan kotoran atau noda tersebut. Karena kayu polos akan lebih memperlihatkan kondisi kotor dibandingkan dengan kayu yang memiliki ukiran (Royani, 2011).

Ornamen Gigi Balang secara bentuk memiliki berbagai macam jenisnya. Ciri Khusus dari Gigi Balang yaitu adanya bentuk dasar segitiga kebawah dan persegi panjang yang tersubstraksi oleh bidang setengah lingkaran pada tepinya. Berikut 
adalah rasio panjang segitiga, lebar segitiga, persegi dan diameter setengah lingkaran (Wardi, et al., 2016).
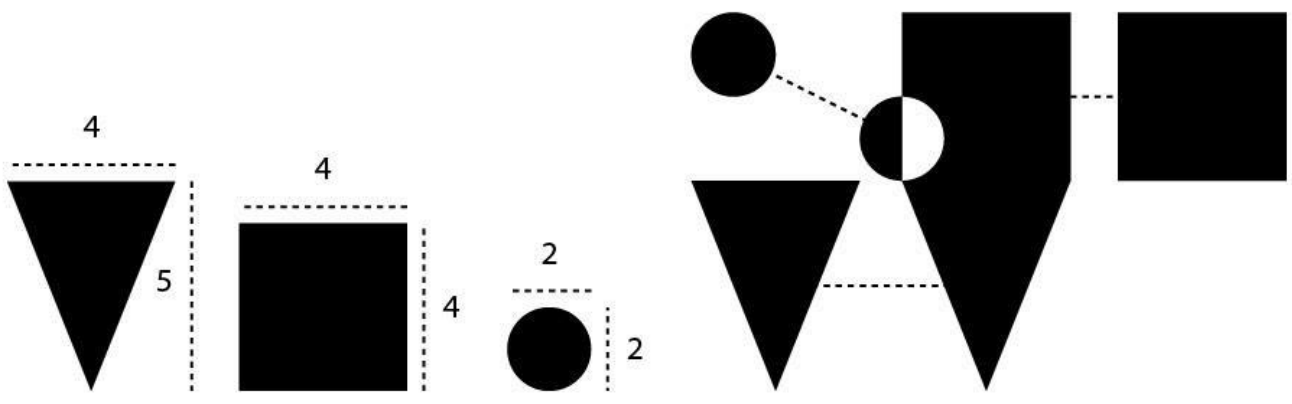

Gambar 3 Bentuk dasar ornamen Gigi Balang betawi pinggir Sumber: ilustrasi oleh Aulia, 2020

Berdasarkan hasil beberapa penelitian sebelumnya keberagaman geometri ornamen rumah Betawi dalam lingkup hunian memiliki faktor penyebab diantaranya status sosial, usia pembuatan ornamen dan latar belakang pemilik rumah. Namun belum ada yang mengkaji penggunaan ornamen Budaya Betawi dalam lingkup yang lebih besar seperti infrastruktur Kota. Sesuai dengan peraturan gubernur nomor 11 tahun 2017, dalam penggunaan ornamen Gigi Balang dipilih sebagai identitas infrastruktur Kota Jakarta (JakartaTourism, 2015). Oleh karena itu penulis akan mengkaji efektivitas penggunaan ornamen Gigi Balang sebagai identitas pada infrastruktur Kota Jakarta. Penelitian ini dilakukan karena belum adanya penelitian sejenis sebelumnya.

Penelitian sebelumnya berfungsi memperkaya pembahasan penelitian ini, dikarenakan belum adanya penelitian sejenis. Dalam penelitian ini disertakan jurnal penelitian sebelumnya yang berkaitan dengan motif, budaya, ornamen dan teori yang mendukung. Artikel dengan judul Pendokumentasian Aplikasi Ragam Hias Budaya Betawi pada Desain Interior Ruang Publik Café Betawi, pada jurnal Humaniora oleh Amarena Nediari dan Grace Hartanti pada tahun 2015 memaparkan beberapa jenis ragam ornamen hias Budaya Betawi pada desain 
interior ruang publik. Salah satu ornamen tersebut merupakan lisplang Gigi Balang dan ornamen lainnya seperti banji, langkan, bunga melati dan matahari. Ornamen serta warna pada Budaya Betawi mengandung makna tersendiri sehingga dalam penerapannya mempunyai aturan dan juga perhatian khusus. Berdasarkan penelitian ini penerapan ragam hias dan warna Budaya Betawi pada public space terlihat pada penggabungan elemen serta penerjemahan konsep secara visual yang selaras meskipun telah berbaur dengan unsur modern.

Geometri Ornamen Pada Fasad Rumah Tinggal Betawi Pinggir (Studi Kasus: Bale Kambang Condet) pada Jurnal Mahasiswa Jurusan Arsitektur tahun 2015 oleh Farah Ahlamia Wardi, Antariksa dan Noviani Suryasari mengidentifikasi dan menguraikan unsur pembentuk ornamen pada fasad bangunan arsitektur Betawi pinggir dengan menggunakan metode analisis deskriptif dan purposive sampling. Terdapat beberapa pengelompokan ornamen pada pengamatan yang didapat yaitu Ornamen Gigi Balang, banji, pucuk rebung, geometris pada pintu, kubah, ginggang, sekor sulur, flora geometris, dan tapak jalak. Faktor keberagaman tersebut dilatarbelakangi adanya status sosial, usia ornamen serta latar belakang pemilik hunian.

Rujukan metode penelitian ini ada pada artikel Fenomena Perubahan Bentuk Mobil Toyota Kijang Generasi I (1977), Generasi li (1981) dan Generasi lii (1986) sebagai Representasi Dari Keinginan, Kebutuhan, dan Daya Beli Masyarakat Penggunanya di Indonesia pada jurnal Artic tahun 2019 oleh Ahmad Nurzaeni Fauzi. Metode analisis penelitian ini menggunakan Prinsip Totalitas, Waktu, dan Nilai yang dikemukakan oleh W.H. Mayall dan dikembangkan oleh Dr. Ahadiyat Joedawinata untuk menganalisis fitur-fitur yang terdapat pada komponen eksterior dan interior mobil Toyota Kijang, dan membedah faktorfaktor apa yang hilang, apa yang berubah, apa yang tetap, dan apa yang baru dari ke-3 generasi Toyota Kijang. Dari hasil penelitian dapat disimpulkan bahwa pada sebuah desain aspek fungsi (performance) dan estetika (form) saling berkaitan 
satu sama lain, terjadinya perubahan pada salah satu aspek mempengaruhi aspek yang lain. Teori Perubahan yang dikemukakan oleh Ahadiyat Joedawinata tahun 2017 diterapkan pada penelitian ini dengan tujuan menganalisa poin yang paling menonjol dari tiap bagian Teori Sembilan Unsur Pemandu terkait dengan terciptanya ornamen Gigi Balang sebagai identitas visual infrastruktur Kota Jakarta.

\section{METODE PENELITIAN}

Penelitian ini menggunakan metode kualitatif dan kuantitatif (mixed method). Teknik pengumpulan data yang digunakan yaitu observasi, wawancara, kuesioner, dokumentasi, dan studi pustaka. Tujuan penelitian untuk menganalisis tingkat efektivitas Gigi Balang sebagai identitas Kota jakarta yang dikaji melalui beberapa aspek yaitu; aspek bentuk, waktu, tempat dan fungsi utilitas berdasarkan teori Mayall tahun 1979 dan dikembangkan oleh Dr. Ahadiat Joedawinata (Fauzi, 2019). Observasi dilakukan secara langsung oleh peneliti pada titik-titik tertentu yang terdapat ornamen Gigi Balang seperti lisplang, rumah adat Betawi, kerajinan khas Betawi, alat kesenian serta beberapa penerapan pada infrastruktur Kota Jakarta seperti jalan layang antasari, halte TransJakarta Pondok Indah 2, underpass Matraman.

Wawancara dilakukan terhadap budayawan Betawi yaitu Bapak Untung Jaya pada tahun 2018, yang bekerja sebagai ketua RT 12, RW 08, di Kampung Betawi Srengseng Sawah, Jagakarsa untuk mendapatkan informasi mengenai ornamen Gigi Balang. Kemudian untuk survei terhadap responden dilakukan penyebaran kuesioner secara acak kepada masyarakat Kota Jakarta yang sedang mengikuti acara Car Free Day (Hari Bebas Kendaraan) secara langsung. Car Free Day dipilih sebagai lokasi survei karena dianggap menjadi pusat berkumpulnya berbagai etnis yang merepresentasikan penduduk yang tinggal di Kota Jakarta. 
Dokumentasi dilakukan dengan cara mengambil dan mengamati foto ornamen Gigi Balang dari berbagai sumber. Dalam hal ini penulis mencari sumber dari internet dan studi lapangan. Studi pustaka yang dilakukan dengan mencari sumber tulisan dan artikel yang berkaitan dengan Gigi Balang.

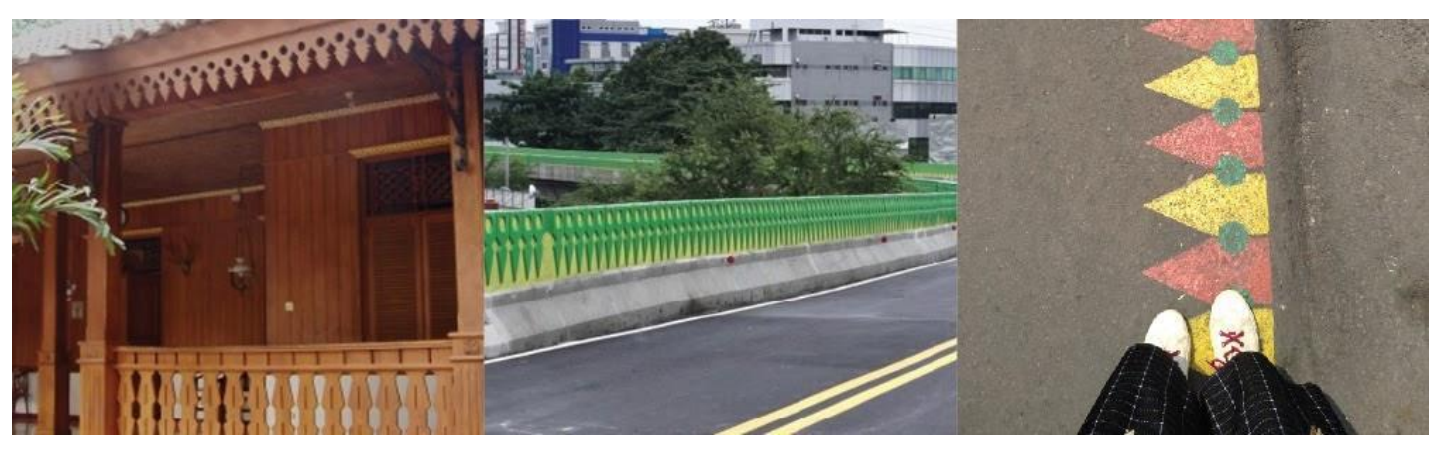

Gambar 4 Pengaplikasian Gigi Balang Sumber: foto oleh Aulia, 2020

\section{HASIL DAN DISKUSI}

Berdasarkan hasil wawancara dengan Bapak Untung Jaya, dapat disimpulkan bahwa kini penggunaan ornamen Gigi Balang telah mengalami sedikit perubahan. Ornamen ini sempat tergeserkan oleh karena masuknya budaya asing ke Jakarta terutama bagi budaya Betawi Kota. Ornamen Gigi Balang mulai sering terlihat lagi semenjak adanya Perda No.4 Tahun 2015 tentang Pelestarian Kebudayaan Betawi serta Pergub 11 Tahun 2017 tentang Ikon Budaya Betawi. Dengan adanya peraturan ini, warga Jakarta dituntut untuk lebih melek dengan budaya Betawi sebagai identitas tunggal. Bahkan ornamen ini juga dapat kita jumpai pada mainan anak.

Menurut beliau, ornamen Gigi Balang saat ini sudah banyak variasi bentuknya. Dari faktor internal tidak sedikit arsitek Betawi muda yang mengembangkan ornamen ini menjadi suatu bentuk yang baru atau bahkan menerapkan bentuk dasar ornamen ini terhadap objek yang tidak pernah dibayangkan sebelumnya. Dari faktor eksternal, masuknya berbagai macam etnis 
dan budaya mempengaruhi pola atau pemahaman yang ada, namun hal ini tidak lantas menghilangkan esensinya. Justru hal ini yang membuat kebudayaan di Kota Jakarta menjadi lebih beragam.

Beliau juga berpendapat, walaupun ornamen Gigi Balang mudah dijumpai, tetapi masih banyak warga Jakarta yang belum memaknai ornamen tersebut. Kebanyakan dari mereka hanya melihat sebagai ornamen dekoratif yang menghiasi bangunan tanpa mengerti lebih dalam maknanya. Perlunya adanya sosialisasi yang lebih baik untuk mengedukasi masyarakat bahwa budaya Betawi adalah identitas milik warga Jakarta terlepas dari apapun sukunya.

Berikut ini adalah penjabaran data yang berhasil dikumpulkan lewat penyebaran kuesioner pada saat car free day berlangsung. Total Responden yang didapat sebanyak 117 partisipan. Berdomisili di Jakarta sejak tahun 2010 sebanyak 18 responden (15,38\%), antara tahun $2000-2010$ sejumlah 28 responden $(23,93 \%)$ dan sebelum tahun 2000 sebanyak 71 responden (60,69\%). Pendapat mengenai identitas visual yang cocok sebagai identitas Kota Jakarta; ondel-ondel: 65 responden (55,55\%), kembang kelapa: 4 responden (3,41\%), Gigi Balang: 30 responden $(25,64 \%)$, batik betawi: 16 responden $(13,67 \%)$ dan identitas lain seperti elang bondol serta monumen nasional: 2 responden $(1,73 \%)$.

Dari sisi pentingnya identitas visual bagi Kota Jakarta, 110 responden $(94,01 \%)$ merasa perlu adanya identitas visual. Hasil survey tempat yang tepat untuk menampilkan identitas visual Kota Jakarta responden menjawab Sarana transportasi: 39 responden (33,33\%), ruang publik: 73 responden $(62.39 \%)$ dan tempat lain sebanyak: 5 responden (4.27\%). Setuju dengan identitas Kota Jakarta yang perlu diwakilkan oleh Budaya Betawi sebanyak 73 responden $(62,39 \%)$.

Hasil kuesioner terhadap 117 responden, kemudian dilakukan pengelompokan data berdasarkan periode lamanya waktu menetap yaitu; masyarakat yang sudah menetap lebih dari 18 tahun dan yang menetap kurang dari 18 tahun (mulai tinggal di Jakarta dari tahun 2000 atau kurang). Hasilnya lebih 
banyak warga yang sudah menetap lebih dari 18 tahun di Jakarta. Berdasarkan data survei ini dapat disimpulkan bahwa tidak terjadi pertambahan penduduk yang signifikan dari luar Jakarta sejak tahun 2000. Dari hasil kuesioner juga didapatkan fakta bahwa dari 117 responden hanya 4 orang yang benar-benar mengenal dan paham memahami ornamen Gigi Balang, kebanyakan hanya mengetahui bentuk tanpa mengetahui nama dari elemen dekoratif ini. Bahkan dari mereka ada yang tidak mengetahui sama sekali tentang apa itu ornamen Gigi Balang.

Dalam kuesioner juga diajukan pertanyaan mengenai alternatif identitas yang paling cocok untuk dijadikan sebagai identitas Kota Jakarta. Dalam pengaplikasiannya memang ornamen Gigi Balang umumnya digunakan sebagai elemen dekorasi. Namun berdasarkan penjabaran hasil survei di atas menunjukan bahwa pemilihan ornamen Gigi Balang dinilai kurang efektif oleh masyarakat sebagai identitas Kota Jakarta. Hasilnya menyatakan 65\% responden memilih ondel-ondel sebagai identitas yang lebih dikenal luas, sedangkan 30\% orang memilih Gigi Balang. Berdasarkan data ini dapat disimpulkan bahwa ondel-ondel lekat dengan budaya Betawi.

\section{Teori Perubahan}

Kini penggunaan ornamen Gigi Balang berkembang pesat, pengaplikasiannya merambah ke berbagai bidang, didukung oleh peraturan gubernur no.11 tahun 2017, pengaplikasian ornamen ini tidak lagi hanya terbataskan sebagai ornamen penghias rumah. Menurut Teori Perubahan yang dikemukakan oleh Ahadiyat Joedawinata tahun 2017, tentu hal ini didorong oleh perubahan salah satu dari sembilan unsur dalam terbentuknya sebuah karya desain. Berdasarkan teori ini, terdapat faktor eksternal dan internal yang mendukung dalam terciptanya desain sebuah produk. Sembilan aspek ini berkaitan antara satu dengan yang lain dalam penciptaan sebuah desain produk yang baik. Keterkaitan antara ruang dan waktu serta unsur-unsur berada di 
dalamnya seperti kondisi alam, fungsi atau utility, serta bahan baku yang tersedia dipadukan menjadi suatu produk dengan memanfaatkan skill yang dimiliki sehingga melahirkan satu desain sebuah produk yang berfungsi baik sebagai solusi sebuah permasalahan (Joedawinata, 2017).

\section{UNSUR PEMANDU DALAM PROSES TERBANGUN DAN MEMBENDANYA SATU GAGASAN MENJADI OBJEK TERWUJUD}

MANUSIA SEBAGAI
MAHLUK
1. ALAM / BIOFISIK
2. PSYCHO
3. SOSIO EKONOMIK
BUDAYA - SPIRITUAL
BUDAYA - SPIRITUAL

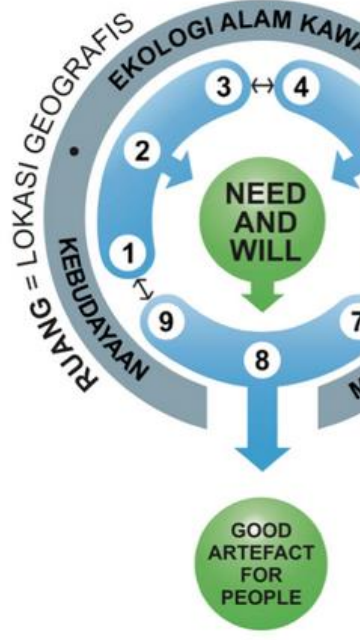

MEMBUTUHKAN AKAN OBJEK PRODUK DENGAN MUATAN

4. FUNGSI PRAKTIS / GUNA

5. CITRA DAN EKSPRESI ESTETIKA

6. NILAI-NILAI SIMBOLIK STATUS-STATUS SOSIAL, SPIRITUAL KOSMOLOGI DAN LAIN-LAIN.

UNSUR PENDUKUNG DALAM PROSES MEMBENDANYA SUATU GAGASAN

7. MATERIAL

8. TEKNIK - KETERAMPILAN -

PERALATAN

9. ENERGI PEMROSES

Gambar 5 Sembilan unsur pemandu dalam proses terbangun dan membendanya satu gagasan menjadi objek terwujud

Sumber: Joedawinata, 2017



Gambar 6 Adaptasi sembilan unsur pemandu dalam ornamen Gigi Balang Sumber: ilustrasi oleh Aulia, 2020 
Pada bagan yang akan dijelaskan untuk menganalisa poin yang paling menonjol dari tiap bagian Teori Sembilan Unsur Pemandu terkait dengan terciptanya ornamen Gigi Balang sebagai identitas visual infrastruktur Kota Jakarta.

Tabel 1 Lokalitas dan lokal konten suatu kawasan terbangun

\begin{tabular}{clcc}
\hline No. & \multicolumn{1}{c}{ Unsur Hidup Gigi Balang } & \multicolumn{2}{c}{ Kecenderungan Fungsi pada } \\
\cline { 3 - 4 } & & Rumah Betawi & Infrastruktur \\
\hline $\mathbf{1}$ & Unsur Biofisik, Alam dan Manusia & $\mathbf{V}$ & \\
$\mathbf{2}$ & Gejala Psikologis dan Perilaku & & $\mathrm{V}$ \\
$\mathbf{3}$ & Gejala Sosial Budaya dan Ikonnya & & $\mathrm{V}$ \\
\hline
\end{tabular}

Sumber: analisis oleh Aulia, 2020

Pengaplikasian ikon budaya Betawi sebagai identitas tunggal Kota Jakarta menjadi daya tarik tersendiri. Proses akulturasi dari berbagai etnis dan budaya yang telah berlangsung sejak zaman kolonialisme telah membentuk percampuran budaya yang sangat nyata. Hal ini menjadi faktor utama dalam pembentukan ikon dan ragam hias yang secara visual sangat khas dan kaya. Terkait dengan gejala sosial dan ikon budaya yang terus berkembang, pemerintah mengeluarkan peraturan gubernur nomor 11 tahun 2018 mengenai usaha pelestarian budaya Betawi sebagai identitas tunggal Kota Jakarta, pemerintah menyisipkan ornamen Gigi Balang pada infrastruktur Kota. Hal ini masih mengacu kepada fungsi ornamen Gigi Balang sebagai elemen dekoratif sebuah bidang. Meski ornamen Gigi Balang hanya digunakan sebagai ornamen pada lisplang rumah, kini penggunaan ornamen ini juga berfungsi sebagai elemen dekoratif yang meliputi berbagai macam objek.

\begin{tabular}{clcc}
\multicolumn{3}{c}{ Tabel 2} & Lokal konten yang bersumber dari berbagai muatan suatu objek artefak \\
\hline No. & \multicolumn{1}{c}{ Unsur Fungsi/Kebutuhan Gigi Balang } & \multicolumn{2}{c}{ Kecenderungan Fungsi pada } \\
\cline { 3 - 3 } & & Rumah Betawi & Infrastruktur \\
\hline $\mathbf{4}$ & Fungsi Praktis Utilier & $\mathbf{V}$ & $\mathbf{V}$ \\
5 & Ekspresi Estetika dan Elemennya & & \\
6 & Tanda dan Simbol Status & \\
\hline
\end{tabular}

Sumber: analisis oleh Aulia, 2020 
Kebutuhan sebagai eksistensi dalam mempromosikan identitas Kota Jakarta menjadi motivasi utama untuk memajukan sektor pariwisata. Hal ini membutuhkan sebuah media yang masif dan konkrit dalam pengaplikasian elemen visualnya secara estetik. Bertepatan dengan diadakannya perhelatan olahraga yang bergengsi yaitu ASEAN Games 2018, Indonesia sebagai tuan rumah memilih Kota Jakarta dan Palembang sebagai tempat diselenggarakannya acara tersebut. Secara tidak langsung hal ini menuntut pemerintah untuk meremajakan infrastruktur kota sekaligus menjadi ajang untuk mempromosikan kearifan lokal budaya setempat kepada mata dunia internasional. Dalam hal ini, pengaplikasian budaya Betawi dipilih sebagai identitas tunggal Kota Jakarta. Keputusan ini tidak semata-mata dipilih tanpa melihat sejarah panjang Kota Jakarta. Yang mana Kota ini terbentuk atas peleburan budaya yang menjadi satu kesatuan yang nyata. Terkait dengan penelitian ini penggunaan ornamen Gigi Balang kini kini dapat dilihat dalam berbagai infrastruktur khususnya fasilitas umum di Kota Jakarta seperti jembatan, fly over, tiang listrik, dan fasilitas lainnya sebagai media penerapan ornamen dekoratif khas budaya Betawi tersebut.

\begin{tabular}{|c|c|c|c|}
\hline \multirow[t]{2}{*}{ No. } & \multirow[t]{2}{*}{ Eksekusi Gigi Balang } & \multicolumn{2}{|c|}{ Kecenderungan Fungsi pada } \\
\hline & & Rumah Betawi & Infrastruktur \\
\hline 7 & Material & $\sqrt{ }$ & \\
\hline 8 & Teknik-Keahlian-Peralatan & & $\sqrt{ }$ \\
\hline 9 & Energi Pemprosesan (Eksekusi) & & \\
\hline
\end{tabular}

Sumber: analisis oleh Aulia, 2020

Indonesia merupakan negara tropis dengan banyak hutan sebagai sumber bahan baku yang yang melimpah. Hal ini menjadi salah satu faktor yang mendorong pengembangan ornamen Gigi Balang untuk diaplikasikan ke berbagai elemen dekorasi seperti lisplang rumah dan dekorasi lain. Sebagai bentuk dukungan terhadap desain berkelanjutan, kini ornamen Gigi Balang tidak hanya bergantung kepada ketersedian bahan baku kayu yang melimpah. Penggunaan 
material kayu kini sudah tidak menjadi satu satunya alternatif. Hal ini tentu terkait dengan tingkat eksploitasi hutan di Indonesia yang sudah berada di posisi yang cukup mengkhawatirkan.

Penggunaan alternatif material seperti semen dan besi yang tergolong lebih memiliki ketahanan yang baik terhadap faktor pelapukan menjadi pilihan. Keunggulan lain juga dari sistem produksinya yang lebih mudah menggunakan mesin cetak yang dapat mempersingkat waktu dalam proses pembuatan ornamen Gigi Balang untuk memperindah infrastruktur Kota Jakarta.

Teori the principle of value oleh W.H. Mayall tahun 1979 yang awalnya disusun untuk mengatasi masalah keterbatasan dana dalam proses penciptaan suatu objek (Fauzi, 2019). Teori ini mampu diaplikasikan ke dalam berbagai objek termasuk dalam perancangan infrastruktur terhadap identitas Kota Jakarta. Bentuk, waktu, tempat dan fungsi utilitas dijadikan sebagai pokok pembahasan yang akan diteliti terkait tingkatan nilai yang terkandung dalam pembentukan Gigi Balang sebagai identitas Kota Jakarta.

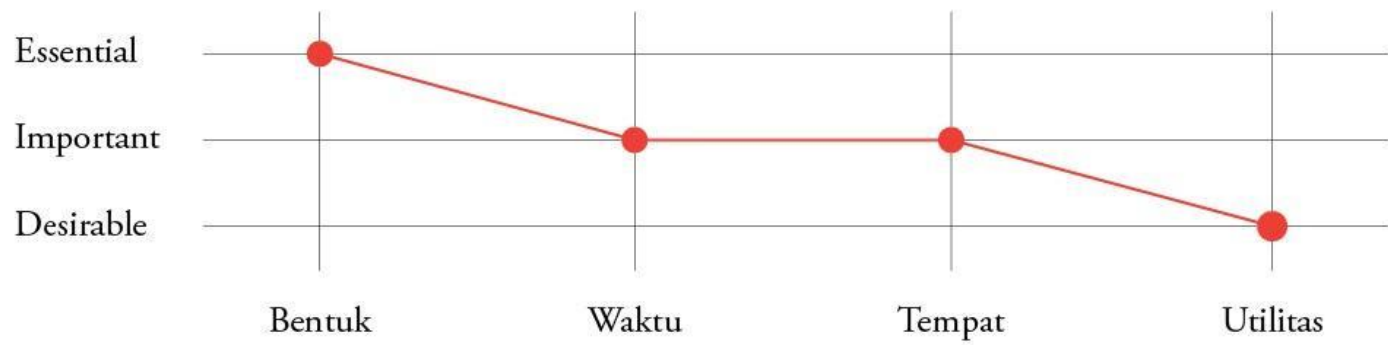

Gambar 7 Bagan the principal of value terhadap Gigi Balang Sumber: ilustrasi oleh Aulia, 2020

Bentuk dinilai menjadi faktor essentials pada pembentukan identitas Kota Jakarta. Terlebih sebagai identitas visual yang menuntut nilai estetika yang diwakilkan lewat bentuk konkrit. Didukung dengan hasil kuesioner, disimpulkan bahwa bentuk ondel-ondel terpilih menjadi alternatif untuk lebih dikembangkan. Terkait hal ini, bentuk yang sesuai dengan pilihan masyarakat menjadi penting 
dalam pembentukan suatu identitas Kota Jakarta. Selain itu dengan pemilihan bentuk yang sesuai, akan berdampak kepada rasa kepemilikan yang kuat untuk para warganya. Dalam kasus ini, kurangnya sosialisasi menyebabkan Gigi Balang dinilai kurang efektif. Bentuk dianggap sebagai sebuah nilai yang penting dalam pembentukan identitas, karena bentuk merupakan hal yang erat kaitannya dengan visual. Pada hakikatnya bahwa manusia akan terlebih dahulu mengenal sesuatu yang dapat dilihat secara visual kemudian menyusul nilai-nilai non abstrak yang terkandung dalam sebuah objek.

Berdasarkan hasil kuesioner dan wawancara yang telah dilakukan, waktu dianggap menjadi unsur penting. Hal ini dilihat dari segi waktu pada saat ini dan waktu zaman dahulu. Dahulu kala pada saat kebudayaan di Jakarta belum begitu banyak, kebanyakan masyarakat masih mengenal ornamen Gigi Balang dan masih familiar dengan ornamen tersebut, namun saat ini ketika globalisasi sudah meluas, banyak kebudayaan masuk yang dibawa oleh orang-orang dari luar Jakarta. Kebudayaan baru tersebut dibawa bersamaan dengan masuknya beragam suku bangsa ke Jakarta. Hal inilah yang menyebabkan Jakarta menjadi kota yang multikultural. Waktu menjadi penting karena dapat mempengaruhi tingkat efektif Gigi Balang. Disisi lain waktu juga bukan merupakan hal yang sangat esensial karena ada hal yang lain yang lebih esensial yaitu bentuk seperti yang telah dijelaskan dalam pembahasan sebelumnya.

Tempat dinilai sangat berpengaruh pada proses sosialisasi suatu identitas visual kota. namun, bukan kuantitas yang harus ditingkatkan, melainkan kualitas lokasi penempatan yang harus diperhatikan. Berdasarkan hasil kuesioner, ruang publik menjadi yang paling banyak dipilih sebagai lokasi yang tempat untuk pemasangan identitas Kota Jakarta. namun pada pengaplikasiannya saat ini Gigi Balang kebanyakan hanya terpasang pada infrastruktur jalanan seperti jembatan layang, jalan lintas bawah, lampu penerangan jalan. Sedangkan ruang publik seperti Medan Merdeka atau dikenal dengan lapangan Monas, taman Menteng 
atau taman Suropati masih jarang ditemukan ornamen Gigi Balang sebagai identitas Kota Jakarta.

Jika mengacu kepada fungsi ornamen Gigi Balang sebagai ornamen dekoratif pada lisplang rumah adat Betawi bisa disimpulkan bahwa ornamen ini tetap difungsikan sebagai elemen penghias. Dahulu dekorasi dalam budaya Betawi menjadi sesuatu yang bersifat desirable (diinginkan) tanpa mengedepankan fungsi guna. Tidak banyak hal yang berubah dalam pengaplikasiannya sekarang sebagai elemen estetik untuk mempercantik infrastruktur Kota Jakarta.

\section{KESIMPULAN}

Berdasarkan uraian di atas dapat disimpulkan bahwa ornamen Gigi Balang perlu mengalami pembaruan baik dalam bentuk, tempat, waktu dan fungsi utilitas. Berdasarkan hasil kuesioner dapat disimpulkan bahwa dari segi bentuk, Gigi Balang dinilai tidak efektif sebagai identitas infrastruktur Kota Jakarta. Dari hasil kuesioner menyatakan bahwa ornamen ondel-ondel paling banyak dipilih sebagai identitas Kota Jakarta. Pembaruan Gigi Balang juga dinilai perlu, pembaruan dari segi bentuk dimaksudkan untuk membuat Gigi Balang tidak kalah saing dibanding ornamen lainnya, pembaruan ini dapat berupa penggabungan ornamen Gigi Balang dengan ornamen lain misalnya batik atau menggabungkan Gigi Balang dan ondel-ondel secara visual.

Dari sisi tempat, hasil kuesioner juga menyatakan bahwa ruang publik lah yang paling banyak dipilih sebagai lokasi pemasangan Gigi Balang. Namun, dari sisi waktu, ornamen Gigi Balang pada saat ini dinilai tepat apabila dihubungkan dengan efek urbanisasi yang telah berlangsung, hal ini dibuktikan pada hasil kuesioner yang menunjukkan bahwa responden masih memilih budaya Betawi sebagai identitas Kota Jakarta tanpa campuran dari budaya luar Betawi. Kemudian 
dari sisi fungsi utilitas, ornamen identitas kedepannya bukan hanya sebagai ornamen hias tetapi juga mengandung fungsi utilitas lainnya sebagai pengikat tambahan antara identitas dengan masyarakat.

Pada akhirnya, peningkatan pada bentuk dan tempat menjadi sorotan pada hasil penelitian terhadap Gigi Balang sebagai identitas visual Kota Jakarta. Perlunya perancangan identitas visual yang lebih dipahami masyarakat menjadi kunci perancangan identitas kota-kota lainnya agar identitas visual efektif untuk merepresentasikan kota sasaran. Pada penelitian yang akan datang diharapkan mendapatkan jumlah responden lebih banyak, memperkenalkan kembali bentuk Gigi Balang sebagai ornamen khas betawi yang kurang dikenal dan juga dapat mengembangkan unsur budaya ataupun ragam hias Betawi lain menjadi sebuah ornamen identitas infrastruktur Kota Jakarta.

\section{DAFTAR PUSTAKA}

Casande, S., 2011. 'Ragam Hias Parang Gerigi Pada Batik Betawi'. DEIKSIS, JuliSeptember, 3(3), pp. 290-303.

Chaer, A., 2012. Folklor Betawi: kebudayaan \& kehidupan orang Betawi. Jakarta: Komunitas Bambu .

Dianty, G. P., 2017. 'Arsitektur Tradisional Rumah Betawi Keturunan'. SCALE, 5(1), pp. 56-65.

Faizah, N., Zid, M. \& Hardi, O. S., 2018. 'Mobilitas sosial dan identitas etnis Betawi (Studi terhadap perubahan fungsi dan pola persebaran kesenian ondel-ondel di DKI Jakarta)'. Jurnal Spatial: Wahana Komunikasi dan Informasi Geografi, 18(1), pp. 36-20.

Fauzi, A. N., 2019. 'Fenomena Perubahan Bentuk Mobil Toyota Kijang Generasi I (1977), Generasi II (1981) Dan Generasi III (1986) sebagai Representasi dari 
Keinginan, Kebutuhan, dan Daya Beli Masyarakat Penggunanya di Indonesia'. ARTic, Volume 3, pp. 113-120.

GoodnewsfromIndonesia, 2018. Ada yang Menarik pada Corak Pagar Pembatas Busway Transjakarta di Koridor 13. [Online] Available at: https://www.goodnewsfromindonesia.id/2018/08/14/adayang-menarik-pada-corak-pagar-pembatas-busway-transjakarta-di-koridor-

$\underline{13}$ [Diakses 2 Januari 2020].

JakartaTourism, 2015. Peraturan Gubernur Provinsi Daerah Khusus Ibukota Jakarta.

[Online]

Available

at:

http://jakarta-

tourism.go.id/2015/sites/default/files/Pergub\%20lkon\%20Budaya\%20Betaw i.pdf [Diakses 3 Januari 2020].

JakartaTourism, 2018. Gigi Balang. [Online]

Available at: https://jakarta-tourism.go.id/visit/blog/2018/02/gigi-balang

[Diakses 3 Januari 2020].

Joedawinata, A., 2017. Applied Aesthetic Dissertation Theory 9 Points, Bandung:

Applied Aesthetic Lecture Materials.

Mayall, W., 1979. Principle of Design. London: Design Council.

Misno, A. \& Prawiro, B., 2016. Reception Through Selection-Modification: Antropologi Hukum Islam di Indonesia. Yogyakarta: Deepublish.

Nediari, A. \& Hartanti, G., 2015. 'Pendokumentasian Aplikasi Ragam Hias Budaya Betawi pada Desain Interior Ruang Publik Café Betawi'. Humaniora, 6(3), pp. 367-381.

Purbasari, M., 2010. 'Indahnya Betawi'. Humaniora, April, 1(1), pp. 1-10.

Rosalinda, H., Pramudita, P. \& Nurcahyawat, E., 2019. 'Budaya Betawi Setu Babakan Dalam Kehidupan Sehari-Hari'. Human Narrative, 1(1), pp. 30-38.

Royani, M., 2011. Konstruksi Atap (Khusus Atap Pelana), Semarang: Universitas Diponegoro. 
Untung, J., 2018. Kampung Betawi Srengseng Sawah, Jagakarsa [Wawancara] (18 November 2018).

Wardi, F. A., Antariksa \& Suryasari, N., 2016. 'Geometri Ornamen Pada Fasad Rumah Tinggal Betawi Pinggir (Studi Kasus : Bale Kambang Condet)'. Jurnal Mahasiswa Jurusan Arsitektur, 4(4).

Windarsih, A., 2013. 'Memahami Betawi dalam Konteks Cagar Budaya Condet dan Setu Babakan'. Masyarakat \& Budaya, 15(1), pp. 177-200.

Windyastuti, B., 2018. Ikon Budaya Betawi Pada Kain Panjang. Karya Seni, Juli. 